\title{
Microscopic Findings Method
}

National Cancer Institute

\section{Source}

National Cancer Institute. Microscopic Findings Method. NCI Thesaurus. Code C117596.

The technique used to administer the microscopic assessment. 